\title{
As políticas culturais brasileiras na contemporaneidade: mudanças institucionais e modelos de agenciamento
}

\author{
* Professor de \\ sociologia e política \\ na Universidade \\ Federal da Fronteira \\ Sul, Campus \\ Erechim. Doutor \\ em ciências sociais \\ pela Universidade \\ do Vale do Rio dos \\ Sinos. Pesquisador \\ vinculado ao \\ Laboratório de \\ Políticas Culturais \\ e Ambientais: \\ Gestão e Inovação, \\ Capes/Unisinos. \\ <rodrigoddsilva@ \\ hotmail.com>.
}

1. Interpretamos as relações entre os atores sociais e as políticas culturais nas quais se engajam mediante o uso do termo "técnica de vida", analogamente ao entendimento empregado por Georg Simmel. Ao descrever as características do tipo metropolitano de homem e suas variantes, acaba por delinear seu entendimento de técnicas de vida, sendo estas entendidas como dispositivos sociais em operação que visam ao ajustamento do indivíduo aos modos de vida na cidade, e sua reação a estes processos (Silva, 2012b). 
2. Para entendermos o sentido de agenciamentos, acompanhamos as elaborações de Yúdice (2004), onde agência posiciona-se, teoricamente, entre a construção das subjetividades e os determinantes sociais da mesma. Assim, agenciamentos são projetos de ação (social) inscritos em regimes de performatividade e objetivados entre a ação do ator e os dispositivos de controle performativo da mesma. mas, em igual teor, nas mudanças globais que parecem atribuir à cultura espaço estratégico nas propostas de desenvolvimento (Yúdice, 2004), de revitalização das urbanidades e de outras formas de consumo de bens culturais (Canclini, 2003).

O ordenamento destas mudanças políticas, em âmbitos estatais, exigiu uma nova organização das agendas políticas, tomando as questões culturais a partir de percepções intersetoriais e interdisciplinares. Além do Programa Cultura Viva, operacionalizado em corresponsabilidade com diversos setores do Estado, outras iniciativas procuraram recorrentes aproximações com as políticas culturais. Poucas foram tão intensas quanto às aproximações e colaborações entre os setores educacionais e de cultura, onde a perspectiva de educar para a cultura, educar para a diversidade, educar para a diferença ou educar para a conservação patrimonial ou das culturas tradicionais ocupou centralidade nas narrativas socioculturais de nosso tempo.

Neste sentido, o presente artigo visa diagnosticar um conjunto de mudanças institucionais sofridas pelas políticas culturais brasileiras na contemporaneidade, em escala nacional, e compreender como tais configurações produziram novas formas de agenciamento cultural ${ }^{2}$ e de ação política, em escalas locais. Para tal, na primeira seção, apresentaremos uma revisão histórica das políticas culturais no Brasil, conforme estudos em literatura específica, a fim de delinearmos apontamentos sobre a natureza diacrônica das mudanças político-institucionais transcorridas no segmento. Na sequência, a partir do relato de pesquisa etnográfica realizada em duas cidades brasileiras - Gramado (RS) e São Luiz do Paraitinga (SP) -, analisaremos a implementação e os modos de ação dos atores nesses processos políticos.

Importa destacar, como prerrogativa teórico-metodológica, nosso interesse em compreender os tensionamentos, contrastes e ambivalências presentes na proposição destas políticas, no âmbito nacional, e os modelos de ação que são ajustados ou regulados nos campos de atuação dos diversos atores, no local. No que se refere às políticas culturais, visamos acompanhar recentes estudos sociológicos que demonstram o quanto tais mudanças políticas reorientam a ação dos atores sociais e potencializam a irradiação de diversos agenciamentos culturais (Canclini, 2003; Yúdice, 2004; Silva, 2011; Silva, 2012a).

\section{Políticas culturais brasileiras: um diagnóstico}

Na década de 1930, ocorreram as primeiras experiências institucionalizadas de políticas culturais no Brasil. A primeira se deu no âmbito municipal (Calabre, 2009), quando Mário de Andrade assumiu o recém-criado Departamento de Cultura e Recreação da cidade de São Paulo, no ano de 1935. Esta iniciativa inaugurou uma tendência das políticas culturais, que se estende à atualidade, qual seja: seu interesse de insti- 
tucionalização. A segunda, no plano nacional, correspondeu à criação do Ministério da Educação e da Saúde, por Getúlio Vargas, sobretudo a partir de 1934, quando Gustavo Capanema assumiu o setor (Calabre, 2009). Tais exemplaridades inauguraram as ações do Estado no âmbito cultural, independentemente de sua regularidade (Rubim, 2011).

As duas primeiras experiências brasileiras expressaram uma forte relação entre o Estado e as políticas culturais. Os projetos desenvolvidos atribuíram centralidade ao Estado, enquanto agente político-cultural, enfaticamente voltados à construção institucional das políticas culturais, embora o ministro Capanema reiterasse que suas prioridades fossem a educação nacional, a saúde pública e a assistência social. Na ocasião em que Mário de Andrade atuava no Departamento de Cultura, em São Paulo, Gustavo Capanema solicitou-Ihe auxílio na formulação do projeto de criação do Serviço do Patrimônio Histórico e Artístico Nacional (Sphan), concluído ainda em 1936 e oficialmente criado em 1937. Essa entidade assumiu inúmeras incumbências no âmbito da administração da cultura, enquanto instância de política pública, tanto na defesa das obras de arte patrimoniais, monumentos, paisagens, folclore, quanto em seu tombamento (Calabre, 2009). Nos percursos históricos que se seguiram, realizar política cultural, sobretudo no plano federal, fazia-se sinônimo de políticas patrimoniais, como nas iniciativas de tombamento oficial e em suas priorizações a obras, objetos e edificações remanescentes do Brasil colonial, face à crescente urbanização.

No mesmo contexto, as questões culturais adquiriram maior importância dentro do campo de planejamento do Estado, passando a figurar entre aquelas áreas vinculadas ao desenvolvimento (Calabre, 2009). Outra questão pertinente, face à ampliação dos dispositivos institucionalizados de administração da cultura, era a falta de recursos financeiros para o setor, traço que configurou uma tendência comum a todas as políticas públicas de cunho social (Vieira, 1983). Esses novos arranjos governamentais potencializaram e permitiram a consolidação de um "mercado de bens simbólicos" (Ortiz, 1988) no Brasil, já iniciado nos anos de 1920, com o rádio.

Se o período histórico compreendido entre os anos de 1930 e 1980, mesmo que de maneira descontínua, pode ser definido como período de responsabilização institucional pelas políticas culturais, especialmente pelo Estado, o ano de 1990 ficou marcado pelo desmonte dos setores governamentais responsáveis pela área. No início deste ano, o presidente Fernando Collor de Mello modificou a estrutura de gestão do Estado brasileiro, desencadeando duas medidas. A primeira foi a dissolução do Ministério da Cultura, que fora criado no governo de José Sarney (1985-1989), e a criação da Secretaria de Cultura. A segunda consistiu na extinção de entidades e organizações públicas atinentes ao setor (Calabre, 2009; Rubim, 2011). Competia, pois, a esta nova Secretaria de Cultura: "preservar e desenvolver o patrimônio 
3. Lei Municipal ก.. 10.923/1991, criada pelo vereador Marcos Mendonça, que permite ao contribuinte o abatimento do IPTU e do ISS, em até $70 \%$, se voltado ao patrocínio cultural. cultural brasileiro, estimular a criatividade artística e promover a preservação da identidade cultural do país" (Calabre, 2009: 108). No entanto, esta reformulação do ordenamento institucional da gestão cultural foi acompanhada por considerável redução orçamentária, afastamento de servidores e esvaziamento de inúmeros projetos e programas, o que se intensifica se considerarmos o quadro de restrição de recursos experimentados nas décadas anteriores. A mudança, contudo, revelou-nos a inauguração de um modelo de orientação neoliberal (Anderson, 1998) nas políticas públicas.

É do ponto de vista do financiamento que mudanças radicais são observadas. Ainda no governo Sarney, em 1986, na gestão de Celso Furtado à frente do ministério, foi

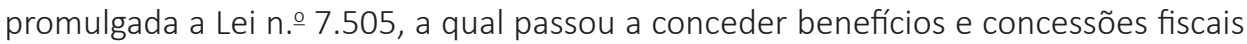
no imposto de renda para iniciativas operacionalizadas no setor cultural ou artístico, isto é, foi instaurado um mecanismo de financiamento das políticas públicas de cultura através de renúncia fiscal. O governo admitia a carência de recursos públicos para o setor, ao reduzir seu financiamento direto, mas observava que as verbas alternativas deveriam ser buscadas no mercado (Rubim, 2011). As palavras do ministro Celso Furtado reiteraram o sentido das mudanças transcorridas nos processos de financiamento, pois enfatizara que em "uma sociedade democrática as funções do Estado no campo da cultura são de natureza supletiva" (Furtado apud Calabre, 2009: 102). Assim entendido, as comunidades e os agentes culturais seriam responsáveis pelos esforços de ação patrocinadora, sendo este um pressuposto fundamental da lógica de implementação das leis de incentivo à cultura.

Com a chegada de Fernando Collor à Presidência da República, a Lei Sarney foi dissolvida. Porém, tal dissolução não pode ser pensada como um ocaso desta estratégia política de financiamento, mas sua passagem por um curto período de atualização. Vários estados e municípios propuseram programas de financiamento semelhantes, caso da Lei Mendonça, ${ }^{3}$ em São Paulo, e o Faz Cultura, na Bahia. Por outro lado, desde a Constituição de 1988, maior autonomia foi atribuída aos municípios nos processos de gestão e procedimentos de elaboração das políticas públicas de cultura, no entanto, ao recorrerem às lógicas das leis de incentivo, "estes governos ajudaram a consolidar no imaginário brasileiro de que o Estado não deveria ser o responsável direto pelo financiamento da cultura" (Rubim, 2011: 28).

As políticas de incentivo foram a única estratégia de financiamento das iniciativas culturais no governo Fernando Henrique, diante de uma grande demanda por projetos versus a limitação de recursos (Yúdice, 2004). Então, a saída foi o estímulo permanente para que grandes empresas investissem no setor, não apenas por renúncia fiscal, mas também associando a iniciativa à visão empresarial, através de marketing cultural. Em pesquisa realizada pela Fundação João Pinheiro sobre o decênio 1985-1995 
acerca de investimentos da iniciativa privada em cultura, 53\% das empresas consultadas nomeou o marketing cultural como principal meio de divulgação de suas marcas, preferindo mesmo investir prioritariamente em: música, audiovisual, patrimônio histórico, artes cênicas e produção editorial (Cury, 2002).

Embora o incentivo fiscal seja uma estratégia que pode trazer benefícios às pessoas envolvidas, dois problemas acompanham tal expediente: a exclusividade desta estratégia como política cultural de governo reduz o poder de intervenção do Estado no setor, bem como a potencial intervenção do mercado realiza-se sem utilização importante de recursos privados, apenas com recursos de renúncia fiscal (Rubim, 2011). O Estado omite-se assim de um papel mais propositivo nas temáticas do setor, caracterizando uma evidente retração de sua ação (estatal). Em todo caso, observamos um movimento de reversão à tendência das políticas culturais efetuadas no período histórico anterior, as quais estavam baseadas na responsabilização institucional das iniciativas políticas e, neste momento, desde a consolidação das leis de incentivo e iniciativas correlatas, os próprios atores responsabilizam-se pela busca de recursos, em fontes diversas, que subsidiem seus projetos culturais, havendo, pois, uma responsabilização individual.

Em 2003, Luiz Inácio Lula da Silva assumiu a Presidência da República e Gilberto Gil incumbiu-se da pasta da Cultura. O ministério foi reformulado e foram criadas novas secretarias, dentre essas a de Políticas Culturais, a de Fomento e Incentivo à Cultura, a de Programa e Projetos Culturais, a do Audiovisual e a de Identidade e Diversidade Cultural, com ênfase na produção de uma postura ativa do Estado no setor. Associado ao manifesto e efetivo interesse ministerial em democratização cultural (Chauí, 2006), uma nova lógica de distribuição de recursos e implementação de políticas passava então a ser efetuada:

Ao longo da primeira gestão do ministro Gil, algumas medidas foram tomadas para buscar diminuir o processo de concentração regional e setorial. Uma delas foi investir no processo de seleção de projetos por meio de editais, tanto internos, quanto por intermédio dos maiores investidores na lei, como é o caso da Petrobras (Calabre, 2009: 122).

As mais consistentes críticas da equipe ministerial aos governos anteriores referiam-se aos mecanismos de financiamento através das leis de incentivo. Segundo estes, "os incentivos fiscais não direcionariam recursos segundo prioridades políticas, deixando às empresas a decisão sobre a alocação final dos recursos públicos" (Barbosa, 2008: 78), o que fragilizava a ação do Estado. Outra limitação observada dizia respeito à sua reduzida abrangência territorial, sobretudo se considerarmos a concentração dos recursos na Região Sudeste do Brasil. Estava na agenda do novo ministério 
uma reestruturação mais ampla das políticas culturais, a qual estava baseada em dois procedimentos, fundamentalmente: o Plano Nacional de Cultura e o Sistema Nacional de Cultura. Desde o início de 2005, as ações ministeriais estavam voltadas para um Plano Nacional, mediante este interesse, foi realizada a I Conferência Nacional de Cultura, cujas reuniões preliminares seriam municipais, estaduais e interestaduais, com a finalidade de colher subsídios para o plano (Calabre, 2008). Consoante ao processo, encontrava-se o Sistema Nacional de Cultura, com o objetivo de voltar-se para ações integradas no setor, evitando distorções e sobreposições de iniciativas e legislações, o que vinha ocorrendo com as leis de patrimônio histórico e cultural, por exemplo.

Não obstante as inúmeras ações sugeridas para a cultura no período administrativo do presidente Lula, uma delas, a nosso ver, tornou-se exemplar das novas estratégias postas em operação pelo Ministério da Cultura: o Programa Cultura Viva. Criado pela Portaria Ministerial n.ำ156/2004, este programa visava à articulação de cinco ações: Pontos de Cultura, Agentes Cultura Viva, Cultura Digital, Escola Viva e Griôs-Mestres dos Saberes, com o objetivo de promover o acesso à fruição, produção e difusão cultural, por meio de mecanismos de cooperação social. As seleções de projetos davam-se através de editais, como ilustra a citação abaixo:

\footnotetext{
As seleções seriam feitas por meio de editais públicos e cada projeto de Ponto de Cultura selecionado receberia recursos da ordem de $\mathrm{R} \$ 150$ mil ao longo de cinco semestres e também passaria a ser beneficiado por ações e parcerias formalizadas pelo Ministério da Cultura (MinC), visando à ampliação das atividades realizadas (Calabre, 2009: 124).
}

Embora o financiamento das políticas governamentais ainda estivesse dependente das leis de incentivo, estas ações realizaram uma aproximação e um diálogo com setores da sociedade que antes não estavam presentes na agenda de discussões públicas, além de contemplar financiamento e interesse político a agentes culturais que não receberiam em circunstâncias anteriores, como mestres da cultura popular, interiorizando geograficamente estas políticas, como explicita Silva (2011). Embora o quadro de redução orçamentária não tenha sido alterado com consistência, o Programa Cultura Viva ampliou as possibilidades de obtenção de recursos e permitiu que inúmeros projetos recebessem fomento estatal, constituindo um campo concorrencial mais ampliado. Em nossa análise, este campo concorrencial - observado nos projetos de Pontos de Cultura - reforça a tendência à responsabilização individual por seus projetos e pela obtenção de financiamento público ou privado para sua implementação. Mesmo com a nova atitude ministerial, a escassez de financiamento, associada aos dispositivos concorrenciais através de editais, conformam e acentuam estes campos de disputa por recursos. 
Além disso, o Programa Cultura Viva incorpora uma segunda mudança fundamental no período administrativo de Lula: a pluralização da questão identitária. A própria identidade nacional - tema prioritário das políticas culturais na era Vargas - torna-se pluralizada, como diagnostica Alexandre Barbalho (2007):

\begin{abstract}
A diversidade não se torna uma síntese, como no recurso à mestiçagem durante a era Vargas e na lógica integradora dos governos militares, nem se reduz à diversidade de ofertas em um mercado globalizado. A preocupação da gestão Gilberto Gil está em revelar os brasis, trabalhar com as múltiplas manifestações culturais, em suas variadas matrizes étnicas, religiosas, de gênero, regionais etc. (Barbalho, 2007: 52).
\end{abstract}

Esta percepção revela o interesse do Estado em contemplar, em seus campos de intervenção, atores e grupos antes não reconhecidos pelas ações ministeriais - caso das culturas populares (Silva, 2012). Na visão de Célio Turino, então coordenador do programa, essa perspectiva implica um Estado ampliado, promotor de acesso aos meios de formação, criação e fruição de experiências culturais, mediante vínculos de parceria com agentes culturais, artistas, professores e militantes sociais, atento às mudanças culturais de nosso tempo. No entanto, algumas questões acabam ficando em aberto:

- Como alcançar essas metas em contextos de limitações de recursos?

- Como obter democratização cultural, na acepção de Chauí (2006), em programas consolidados por lógicas concorrenciais por projetos e recursos?

- Como estas mudanças contemporâneas nas lógicas de implementação das políticas culturais são incorporadas às cidades brasileiras, na atualidade?

- Quais possibilidades de ação efetivamente se colocam para os agentes e as instituições culturais?

Diante deste campo de problematizações sociológicas, constatamos que estas mudanças institucionais sofridas pelas políticas culturais brasileiras na contemporaneidade se traduzem em diversas lógicas e princípios de ação nas escalas locais. Para tal análise, estaremos expondo as experiências em políticas culturais de duas cidades brasileiras, Gramado (RS), e São Luiz do Paraitinga (SP), as quais estudamos através de exercício investigativo entre os anos de 2009 e 2011.

Os dados sobre as questões citadas advêm do acompanhamento sistemático das formas de implementação destas políticas culturais, tanto mediante a coleta de dados 
etnográficos, quanto de realização de entrevistas semiestruturadas com agentes e gestores atuantes no campo, ou mesmo da coleta de material de divulgação das mesmas na mídia regional. Neste sentido, as duas próximas seções terão como fundamento empírico a investigação citada.

\section{Agenciamentos culturais de Estado: a experiência de Gramado (RS)}

Situada na região serrana do estado do Rio Grande do Sul, distante cerca de $120 \mathrm{~km}$ da capital, Porto Alegre, Gramado é um dos principais polos culturais e turísticos regionais. Por um registro histórico, cumpre mencionarmos que foi no ano de 1875 que chegaram às terras do atual município os primeiros colonizadores, fixando-se no local conhecido como Linha 28. Eram predominantemente imigrantes italianos e alemães que ali se estabeleceram, os quais foram, pouco a pouco, fundando as primeiras localidades e distritos rurais. As décadas de 1910 e 1920 trouxeram possibilidades de construção de espaços mais urbanizados, com as instalações de uma capela da Igreja Católica, uma agência dos Correios e outra do Banco Nacional do Comércio, seguidas por exatoria estadual, iluminação pública, a chegada da viação férrea e, na esteira destas transformações, a sede distrital passa ao atual centro do município. Às décadas posteriores estavam reservadas novas mudanças: a presença de um cinema, de escolas, a construção da Igreja Matriz, de dois hospitais, o primeiro asfaltamento da rua central, além do crescente desenvolvimento industrial e comercial.

Em 1958, Gramado produziu o primeiro evento de rua que serviu de alavanca para o desenvolvimento de eventos culturais e turísticos: a "Festa das Hortênsias", evento realizado até meados da década de 1980 e, como vemos, inseriu o município nas lógicas do turismo nacional, até a contemporaneidade. Na sequência histórica, uma série intensa de eventos passou a ocupar a população local e os turistas: Festival de Cinema, Festa da Colônia, Natal Luz, Gramado Cine Vídeo, além de inúmeros eventos de turismo de negócios e de outras naturezas. Este crescente exigiu um significativo desenvolvimento de setores voltados à prestação de serviços e ao atendimento aos públicos turísticos, como atividades dirigidas à hospitalidade, hotelaria, gastronomia, infraestrutura urbana, transportes e comunicação social.

Esta situação explicita, em boa medida, os interesses sociais, econômicos, políticos e culturais em jogo nas atividades turísticas (Silva, 2012a). Para complementarmos o diagnóstico, precisamos ainda considerar os dados recentemente disponibilizados pela Secretaria Municipal de Turismo, a saber:

1. no primeiro semestre de 2011, de janeiro à julho, Gramado recebeu 2,1 milhões de turistas; 
2. a primeira quinzena de julho do mesmo ano, recebeu 200 mil turistas;

3. a expectativa de recebimento de turistas para o ano de 2011 é de 3,6 milhões;

4. os indicadores de fluxos turísticos são crescentes a cada ano, caso da ocupação hoteleira que tem o aumento médio de $2 \%(2010-2011){ }^{4}$

O turismo, em Gramado e na Serra Gaúcha, é evidenciado como vetor e prerrogativa das políticas de desenvolvimento da região, tomando principalmente as atividades e manifestações culturais como "reserva disponível" (Yúdice, 2004) para projetos culturais neste tempo, produzidos a partir de narrativas de permanente atratividade ao público visitante e na captação de projetos culturais interessantes aos exigentes viajantes de hoje. A "Abertura" de um encarte especial veiculado pelo Grupo Editorial Sinos, de circulação estadual, chamado "Roteiros da Serra", dá destaque aos usos potenciais da cultura em um contexto situacional "Onde tudo acontece":

Onde tudo acontece

Durante o inverno, a Serra Gaúcha se transforma num dos destinos turísticos mais desejados do país. Para isso, centenas de agências e operadoras de turismo criam pacotes buscando atrair diversos públicos. Muitas famílias programam alguns dias de descanso nesta época do ano, e aproveitam para conhecer esse destino que é tão propagado Brasil afora.

O viajante de hoje está cada vez mais exigente e conectado a um mundo de opções em se tratando de viagens. Por isso, é preciso ser bom nesse negócio chamado turismo.

Ao longo de décadas, a vocação para bem-receber que surgiu em cidades como Gramado, Canela e Nova Petrópolis passou a impulsionar a economia dessas comunidades com cada vez mais ênfase.

Por isso, muito antes da chamada alta temporada, esses municípios planejam novas atrações para surpreender quem chega. E esse desafio é superado graças à sintonia dos poderes públicos com a iniciativa privada.

Assim, a todo o momento surgem novos eventos e novos negócios. Compras, hospedagem, gastronomia, lazer e entretenimento estão combinados com elegância. É na Serra Gaúcha onde tudo acontece. $^{5}$

O provocativo editorial do encarte parece construir apenas uma narrativa de publicidade turística dirigida a um público regional, sobretudo por enfatizar virtuosidades destas cidades situadas geograficamente na Serra Gaúcha. Revela-nos que as ideologias da "vocação natural" e da "latência dos potenciais de atratividade" são

4. "Apelo serrano", "Caderno Dinheiro", Zero Hora, 24.07.2011: 7

5. Roteiros da Serra n. 2, Grupo Sinos, Ago./2011: 2. 
discursos produzidos desde práticas observadas em situações empíricas específicas, ou seja, são construções ou reconstruções político-sociais que inventam e promovem um dos destinos turísticos mais visitados do país, notadamente explicitadas em técnicas de vida (Simmel, 1946) que o texto acima parece expor: planejamento permanente, eminência de operadoras de turismo e viagens, projetos de novos eventos e negócios, "sintonia" entre os poderes públicos e a iniciativa privada.

Se a Festa das Hortênsias, no fim da década de 1950, inaugura uma lógica de intervenção cultural na cidade, com a presença cada vez maior de turistas e visitantes, o Festival de Cinema, iniciado em 1973, e o Natal Luz, em 1987, consolidam estes cursos de ação possíveis (Schutz, 1974). O turismo, em suas diversas frentes de trabalho (cultural, eventos, agroturismo, ecoturismo etc.), enraizava-se como potencial estratégia política, econômica e cultural em Gramado. É neste período que se torna setor e, a posteriori, adquire estatuto de secretaria na gestão pública do município. O mesmo não aconteceu com a cultura. Enquanto intervenção de Estado, esta área não conseguia fortalecer-se como unidade autônoma de gerenciamento de recursos econômicos e políticos, ora atrelada à educação, ora subordinada ao turismo, aliás, tendência presente em várias localidades do país.

Somente no fim da primeira década de 2000 foi observada a necessidade de construir uma Secretaria Municipal de Cultura, ainda que, mediante os arranjos políticos locais, verificou-se a implementação desde um estágio intermediário, uma subsecretaria. O advento de mudanças na organização das políticas nacionais para a cultura, associadas a uma série de editais para fomento cultural publicados na gestão Gilberto Gil e sua necessidade de autonomizar as políticas culturais nos âmbitos locais trouxeram a exigência desta ação, isto é, a formação da subsecretaria representava a inserção em modelos de gerenciamento cultural que, até então, não eram estabelecidos no município, pois sua ênfase estava na captação de recursos na iniciativa privada e em leis de incentivo.

Em 2009, a subsecretaria inicia atividades e suas primeiras ações demonstram indícios de uma técnica de vida que determina os agenciamentos culturais contemporâneos, qual seja, a racionalização. A primeira iniciativa foi então a produção de diagnósticos sobre a produção, a circulação e o consumo culturais em Gramado, envolvendo os próprios agentes nestes procedimentos e, segundo seu idealizador, invertendo o processo de produção dessas políticas públicas, no que respeita a concepção, a execução e a gestão dessas políticas desde os implementadores (Souza, 2003). Neste sentido, foram criadas instâncias participativas no intuito de possibilitar a incorporação de indivíduos aos processos - os fóruns culturais -, onde cada segmento teve seu próprio fórum de representação. Estes eventos tiveram um primeiro caráter global, com a participação de todos os segmentos que contribuíram 
ao trazerem suas críticas, sugestões e ideias para a composição de um plano de gestão, com viabilidade, a ser desenvolvido nos quatro anos da gestão, e, em seguida, fóruns especializados focalizados em demandas pontuais para cada um dos segmentos.

Através destes instrumentos, foram coletados indicadores de prioridade, recebidas sugestões e objetivos que deveriam ser considerados no processo de produção destas políticas culturais, ou seja, obtiveram informações que subsidiaram parâmetros e orientaram ordens de prioridade. Identificaram alguns segmentos com dificuldades de implementação de programas e iniciativas e estes foram destacados, com o objetivo de fortalecer a produção cultural. Frente a esta meta, as parcerias com a iniciativa privada foram utilizadas.

O relato de nossos informantes explicita o interesse de encaminhamento da produção cultural aos mercados turísticos locais, consubstanciados pela necessidade de permanente atratividade em cidades turísticas, o que produziria novos arranjos nas relações entre o local e o global, sobretudo por terem identificado, anteriormente, uma predominância de produtos importados. O artesanato, por exemplo, deveria operar constantemente pela construção de uma imagem idealizada de cidade turística, assim sendo, os bordados, as camisetas, os artefatos domésticos (como aventais, facas, xícaras, suportes diversos) reproduziriam ícones e imagens de Gramado, assim como pressupostos de uma produção racional, formalizada e viável economicamente, o que evidencia o interesse pela comercialização destes produtos. Nesta ótica, são impostos limites ou determinantes à produção cultural da cidade sob os ditames de construção de uma cidade turística, ou para o olhar do turista (Urry, 1996).

Atualmente, a entidade dispõe de um levantamento sobre os agentes culturais, quantos são, seu gênero, em que eventos trabalham. A secretaria assumiu um papel central nos agenciamentos culturais da cidade:

A partir de hoje, a secretaria também começou a atuar como agente, porque um promotor liga pra cá e diz que está precisando de um músico tradicionalista, nós temos uma relação e encaminhamos, hoje o promotor de eventos tem acesso a essas informações diferentemente de outros anos. Além disso, nós percebíamos que apesar de atuar como agente, algumas bandas, principalmente as independentes e aquelas juvenis de rock e pop, não tinham como se encaixar nesse perfil de eventos que habitualmente se utilizam de Gramado como sede, os congressos, as feiras e os encontros (Daniel, gestor cultural).

A entidade detém e centraliza informações detalhadas dos atores culturais da cidade, assim como agencia produtos e práticas culturais nos mercados turísticos locais. Para 
aqueles que não se enquadram nas ações solicitadas, outros eventos são promovidos, muitos destes com uma finalidade social, ou de proteção social (Castel, 2004), em entidades assistenciais ou escolas. Assim, a entidade operacionaliza agenciamentos de coletivos de atores culturais, com duas finalidades específicas: agenciar para promover a inserção de agentes em fluxos da economia da indústria do turismo (Urry, 1996) e a produção de circuitos alternativos para aqueles que não se enquadram nos modelos turísticos, atribuindo-lhes conteúdos de finalidade social. Em todo caso, a secretaria centraliza os modos de produção cultural do município.

Neste campo de agenciamentos, a secretaria estabeleceu uma hierarquia de prioridades, as quais desencadearam a criação do Sistema Municipal de Cultura, inspirado no Sistema Nacional de Cultura. Esta discussão tem subsidiado a formulação do Plano Municipal de Cultura, em fase de redação, que visa planejar o próximo decênio. No entanto, um dos grandes desafios impostos a este modelo de agenciamentos de Estado, mobilizado pela secretaria, refere-se ao financiamento cultural. Neste sentido, aliadas a uma narrativa de escuta ao agente cultural, como informante privilegiado, modalidades de financiamento estão sendo "inventadas". A lógica concorrencial de projetos submetidos a leis de incentivo, cuja historicidade mencionamos anteriormente, adquire repercussão no contexto municipal, sobretudo por identificarmos estas leis ainda como instrumento privilegiado para provimento financeiro dos principais eventos turístico-culturais de Gramado.

Este modelo de agenciamento cultural, observado neste contexto, atribui centralidade aos agentes estatais como mediadores de projetos e iniciativas culturais na contemporaneidade, ou seja, agenciamentos culturais de Estado. Estes agenciamentos são tangenciados por técnicas de vida (Simmel, 1979), evidentes nos fragmentos discursivos expostos e significativos como determinantes às ações culturais, uma vez que o modelo estabelece limites específicos que condicionam as iniciativas individualizadas ou autônomas. Este modelo opera ainda seletivamente sob quais ações culturais devem estar atreladas eventos turísticos produzidos localmente, ou seja, mobiliza técnicas que arranjam e rearranjam a pluralidade de forças (Simmel, 1946), potencializando usos convenientes destas manifestações socioculturais.

Os referidos agenciamentos de Estado são produzidos em processos formalizados, de ações racionalizadas e burocratizadas (Weber, 1999), de planejamento estratégico de sentido empresarial e voltados à disputa (por) e obtenção de recursos à efetuação de seus projetos. Demonstram, talvez pela proximidade às ações estatais, potenciais de mobilização de agentes e recursos, constituindo-se como única instância mediadora de projetos e programas, na qual os agentes individuais devem integrar-se ao modelo, uma vez que supõe que as lógicas concorrenciais são exógenas ao município. No caso de Gramado, esse modelo de agenciamento corporificou-se na criação 
de uma entidade pública - embora efetivada em parcerias com a iniciativa privada - cuja missão fundamental tornou-se gerenciar projetos culturais, a Associação de Cultura e Turismo de Gramado (ACTG).

Criada em 2004, a ACTG é uma instituição civil de direito privado, sem fins lucrativos, cujo objetivo é "organizar, trabalhar e viabilizar novos e conceituados eventos", além do interesse em "promover palestras para divulgar os modos pelos quais Gramado cria e administra seus eventos" e como trazer "retorno" ao município.

$\mathrm{Na}$ atual estrutura, atuam no desenvolvimento e na gestão dos eventos do município: o Festival de Cinema, a Festa da Colônia, o Festival de Gastronomia, o Natal Luz, além de alguns outros eventos de menor repercussão regional, como a Feira do Livro, a Feira do Artesanato, o Festival de Turismo. Deste modo, a ACTG faz-se parceira na gestão dos recursos públicos que os eventos obtêm. Segundo informações oficiais, a gestão desses recursos públicos investidos deve ser operacionalizada através de uma entidade sem fins lucrativos, função exercida por esta organização. Portanto, possui a função prioritária de elaborar e redigir projetos a serem submetidos a entidades governamentais, gerenciar os recursos agenciados e cumprir as obrigações legais de prestação de contas. O objetivo deste planejamento, na maioria das vezes, reside em demonstrar a justificativa para a ação, suas condições de exequibilidade e esclarecimentos sobre sua viabilização econômica e social, portanto demonstrar sua "aproximação à realidade", o que repercutirá no entendimento de sua praticabilidade (Schutz, 1974).

Em seus agenciamentos estatais, a organização negocia com o poder público e com proponentes privados do evento. De certo modo, sua capacidade de agência é tensionada por determinantes advindos de interesses econômicos, sociais e políticos que pesam e influenciam suas próprias proposições políticas. Outros dois desafios a este modelo de agenciamento foram explicitados no âmbito da ACTG, quais sejam: a capacidade autônoma de produção de projetos, sem a necessidade de contratação de especialistas para sua formulação - prática recorrente no meio cultural -, sobretudo nas lógicas de editais seletivos; e a convivência com o risco de indeferimento dos recursos financeiros aos projetos, os quais assumem estatuto de exercício permanente, pois processos de submissão de projetos em editais públicos tornam-se sistemáticos e regulares, como vimos na seção anterior.

Então, o planejamento ou as projeções tornam-se exercícios constantes, procedimento típico destes modelos de agenciamentos de recursos para projetos culturais. Planejar eventos e sua necessária obtenção de recursos financeiros torna-se um imperativo permanente dos agenciamentos estatais, porque sem estes recursos, provavelmente, as políticas culturais e turísticas não se desenvolveriam, independen- 
temente de sua forma, de seu conteúdo ou uso específico. No contexto, cultura e turismo tornam-se indissociáveis.

Não obstante outras situações e conflitos não mencionados aqui, reafirmamos a identificação de um modelo específico de agenciamento cultural, suas características e dimensões praticadas. Os agenciamentos culturais de Estado configuram tipicidades de um modelo de agência que estabelece determinantes que condicionam a ação dos atores no campo cultural. Entendemos que podem ser vários estes modelos, mesmo coexistirem, porém, no contexto situacional descrito, há predominância de um tipo estatal cujas características evidenciamos acima, mas poderiam ser sintetizadas na institucionalização, desde controle racional e burocratizado de Estado, de mecanismos de objetivação das subjetividades dos indivíduos, ou, algo semelhante ao que Simmel $(1946 ; 1979)$ definiu como a objetivação da dimensão humana subjetiva (cultura).

Neste cenário, mecanismos institucionais de Estado tornam-se agências mobilizadoras de recursos para projetos diversificados, mas com unicidade de planejamentos e concentração de interesses em alguns grupos com potencial de negociação com instâncias intermediárias criadas para a formulação de projetos. O campo concorrencial visibiliza-se discursivamente como exógeno ao município e, neste modelo, os projetos individuais dos atores culturais não encontram autonomia ou apoios institucionais, pois a dinâmica do desenvolvimento socioeconômico da cidade depende da efetuação (Schutz, 1974) de projetos com potencial de mercado, para usos turísticos, sendo que estes são predominantes.

\section{Agenciamentos individuais:}

\section{disputas por projetos culturais em São Luiz do Paraitinga (SP)}

São Luiz do Paraitinga é um município localizado no interior do estado de São Paulo, no vale do Paraíba Paulista, distante 170 quilômetros da capital. Do ponto de vista histórico, uma pequena povoação começou a constituir-se no lugar em fins da década de 1760, vindo a constituir-se em vila no ano de 1773, quando seu padroeiro passou a ser São Luís, bispo de Tolosa. No ano de 1857, elevou-se a cidade e, em 1873, elevou-se à denominação "Imperial Cidade de São Luiz do Paraitinga". Data deste período um conjunto de edificações que urbanizaram a pequena cidade, a qual chegou a ter 15 mil habitantes nos anos de 1930, quando a produção de rapadura e derivados de cana-de-açúcar tiveram seu apogeu nos circuitos econômicos regionais. No século XIX, sua economia assentava-se no setor cafeeiro, o qual promoveu o desenvolvimento de toda a região, desencadeando a produção de uma variedade de gêneros agrícolas e tornando-se lugar de abastecimento das tropas que transportavam café do vale do Paraíba para o litoral paulista. O entorno da cidade é marcado 
por belas paisagens naturais, especialmente a floresta remanescente da Mata Atlântica, hoje protegida pela Floresta Nacional da Serra do Mar, criada em 1977 (Lopes, Silva e Silva, 2011).

O desenvolvimento urbano acompanhou um conjunto de transformações sociais, políticas e econômicas ocorridas em âmbito regional, caso da inauguração, em 1927, da rodovia Rio de Janeiro-São Paulo, a qual passava pela nucleação urbana de Taubaté, uma das principais cidades do vale do Paraíba; ou, ainda, o declínio da produção cafeeira na região e a crescente potencialização da indústria como principal estratégia econômica (Lopes, 2006). No entanto, a localização geográfica de São Luiz do Paraitinga a tornou relativamente isolada dos fluxos de modernização desenvolvidos às margens da rodovia Presidente Dutra, o que permitiu a manutenção de certos traços tradicionais de formação da cultura caipira (Lopes, Silva e Silva, 2011).

Muitas de suas edificações históricas tornaram-se patrimônio histórico e cultural mediante processo de tombamento, em 1982, pelo Conselho de Defesa do Patrimônio Histórico, Arqueológico, Artístico e Turístico (Condephaat), entidade vinculada à Secretaria Estadual da Cultura. A partir de então, São Luiz do Paraitinga passou a ser a cidade paulista com o maior número de imóveis tombados como patrimônio histórico e cultural, com mais de 400 unidades. Porém, o caso deste município difere de outros que também abrigam imóveis em semelhantes situações, o fato de a maioria destes serem ainda utilizados como residência. Esse patrimônio arquitetônico tombado, associado à diversidade das práticas culturais, festivas ou religiosas fizeram de São Luiz interessante lugar de visitações turísticas (Silva, 2012b). Então, desde 2002, a cidade tornou-se uma das estâncias turísticas do estado de São Paulo (aprovado pela Lei estadual n.⒒197, de 5 de julho de 2002).

Como observou João Rafael dos Santos (2008), embora indicadores apontem para a existência de êxodo e empobrecimento da população, tornar-se estância turística estadual ampliou com intensidade a arrecadação municipal, pois de R\$ 6,3 milhões, em 2001, passou para perto de R\$ 16 milhões, em 2007 (Santos, 2008). A ampliação da arrecadação expressa a relevância do turismo na economia municipal, graças às atividades de pousadas, hotéis, restaurantes e lojas de artesanato. Tornar-se estância turística trouxe ainda desafios aos modos de organização das políticas culturais na cidade. A política de cultura em São Luiz foi , tradicionalmente, pautada por três traços fundamentais: a política patrimonialista por meio dos processos de tombamento (caso do Condephaat, em 1982, e do Iphan, em 2010); a conformação de calendários regionais festivo-religiosos (festa do Divino Espírito Santo, por exemplo); o tangenciamento das ações sociais às condições instituídas, como a Prefeitura e a Igreja Católica, como sinaliza Santos (2008). 
A priori, os traços acima apontados permitem uma interpretação destas políticas como incrementalistas, porém, as condições turísticas recentes trouxeram novas situações à cidade, novos eventos foram promovidos e outros atores passaram agenciar projetos, dentre estes, os eventos contemporâneos de carnaval, a Sociedade de Observadores de Sacis (Santos, 2008) e o Festival da Música Brasileira. Essas ações, além de uma ênfase nos objetivos econômicos próprios de atrativos turísticos, posicionaram elementos tradicionais da cultura luizense, redimensionando os interesses em jogo diante da atualização midiática observada, por exemplo, a repercussão na mídia regional dos recentes festivais de marchinhas, do carnaval da cidade ou da festa do Divino Espírito Santo (Silva, 2012a; 2012b).

No entanto, algumas modificações significativas em São Luiz ainda estavam por acontecer, estas por fatores inesperados. No primeiro dia do ano de 2010, parte da cidade foi destruída por uma enchente, quando o rio Paraitinga transbordou. Grande contingente da população urbana e rural foi atingida, com perdas e avarias em suas residências, bens móveis, dentre muitas outras perdas sentimentais e simbólicas. O fato foi veiculado pela imprensa brasileira em todos os dias da primeira semana daquele ano e causou comoção geral. Muitos prédios de valor histórico foram danificados (18 foram destruídos e 65 tiveram algum tipo de avaria).

Um caso específico das dinâmicas de "reconstrução social" da cidade que se iniciaram em São Luiz do Paraitinga (Silva, 2012b) parece-nos sinalizar a conformação de outro modelo de agenciamento de recursos às políticas culturais contemporâneas, o qual passaremos a delinear na sequência do texto.

A gestão Gilberto Gil, no Ministério da Cultura, potencializou novos projetos e propósitos para as políticas de cultura nacionais, muito embora suas lógicas fundamentais não trouxessem ruptura substancial com a gestão que Ihe antecedeu. Uma destas novas políticas foi o Programa Cultura Viva.

Como observamos anteriormente, o Programa Cultura Viva e outras políticas culturais produzidas no período administrativo de Lula incorporaram uma mudança importante em suas lógicas organizacionais, qual seja: a pluralização da questão identitária. Essa dimensão do programa parece ter sido usada convenientemente (Yúdice, 2004) no auxílio do município de São Luiz do Paraitinga, após a enchente. Segundo nossos informantes na cidade, havia um edital do programa aberto em 2009, no qual projetos do município foram submetidos, mas nenhum ficou entre os selecionados. Porém, dias depois da enchente, quando se normalizou o acesso ao lugar, a presença de Célio Turino, então coordenador do programa, em São Luiz, consubstanciada ao processo de tombamento das edificações de seu núcleo urbano pelo Iphan, produziu expectativas em torno da seleção emergencial de pontos de 
cultura dirigidos à contribuição nas dinâmicas de reconstrução urbana, o que na sequência veio a ocorrer.

Essa situação promoveu um campo de agenciamentos (de recursos) individuais dos atores voltados à produção de projetos qualificados e à consolidação de parcerias para sua efetuação, num cenário marcado por processos concorrenciais individualizados, embora a prerrogativa da seleção fosse institucional. Porém, além das concorrências, estas disputas revelam-nos outras características de um modelo específico de agenciamento. Para ilustrar tais tendências, relataremos uma experiência de Ponto de Cultura no município: o Ponto de Cultura Fazenda São Luiz.

\section{O Moçambique das Professoras}

Cláudia, 45 anos, professora, natural de São Luiz do Paraitinga, tendo vivido muitos anos em outros municípios do estado, por motivos profissionais. Em 2003, retorna para o município e, na ausência de outras opções profissionais, decide iniciar atividades como professora em uma escola municipal rural próxima de sua residência. $\mathrm{Na}$ escola, começa a envolver-se com grupos de Moçambique, conhece um mestre nesta prática cultural, Raul, que é funcionário da escola e, juntos, iniciam a criação de um grupo de Moçambique, com a participação dos alunos e da comunidade escolar.

Após desenvolverem, voluntariamente, este trabalho por cinco anos - desde 2004 -, a possibilidade de obtenção de recursos para o provimento da iniciativa cultural, através do Ponto de Cultura, trouxe motivações e projetou expectativas de continuidade e ampliação do projeto:

\footnotetext{
Aí, quando apareceu essa ideia do Ponto de Cultura, a gente já tinha um grupo, já desenvolvia esse trabalho há uns quatro ou cinco anos na escola, a gente fazia por conta da gente mesmo, com o dinheiro da gente, gasolina para baixo e para cima, a gente sempre fazia com o que a gente podia, pedindo aqui, com os comerciantes ali, com a escola, que liberava o mestre para a gente ensaiar. Com o Ponto de Cultura, a gente pôde crescer um pouquinho mais, começou a estar unindo o pessoal do Ponto de Cultura, o Moçambique, aí a gente teve até incentivo para estar criando esse outro grupo que você teve oportunidade de ver aqui, que a gente está chamando de Moçambique das Professoras ou Moçambique de São Luiz do Paraitinga (Cláudia, professora).
}

Como Cláudia possuía experiências prévias em promoção cultural e vinha desenvolvendo ações voluntariamente, o Ponto de Cultura despertou interesses de institucionalizar sua atividade com a finalidade de adquirir recursos financeiros. Então, 
ao tomar conhecimento do edital em seus círculos pessoais de relacionamento, foi também informada do agendamento de uma reunião para apresentar a proposta e organizar os interessados para a submissão de um único projeto para o município. Segundo nossa informante:

\begin{abstract}
Aconteceram algumas reuniões aqui, até com o pessoal do Ministério, acho que eles iam ajudar aqui a organizar o trabalho, mas aí eu me senti um pouco meio de fora, porque as pessoas falavam, mas todo mundo na hora de ir para a reunião ninguém falava direito para onde ia, todo mundo escondia um do outro, todo mundo começou a querer fazer o seu (Cláudia).
\end{abstract}

O depoimento da professora evidencia-nos a conformação de um modelo de agenciamento individualizado, pautado nos mecanismos concorrenciais entre agentes no campo, no qual identificamos disputas e conflitos endógenos por interesses e recursos. Mesmo que conforme um campo individual de concorrência, endógeno ao campo cultural, foi necessária a instituição de alianças, sobretudo porque os agentes precisavam de uma entidade proponente, com regularidade de cadastro nacional de pessoa jurídica. O que nos exige recuperar o uso analítico que Georg Simmel (1983) empregou ao conflito, não tomando-o como fator de desagregação social, mas por seus interesses de associação e aliança, isto é, em circunstâncias de competitividade individual, o apoio e a formação de alianças torna-se condição imprescindível. A sequência do depoimento explicita esta conotação:

Quando todo mundo ficou sabendo que precisava ter uma entidade,
todos ficaram meio assim... e o grupo todo que estava estudando, se
reunindo junto para tentar montar um projeto de Ponto de Cultura
para São Luiz, acabou dispersando, acabou indo um para cada lado
e as pessoas ficaram assim [...] todo mundo competindo, um grupo
com o outro ou cada dupla, um amigo aqui, outro ali, e eu quase
desisti de fazer esse projeto, não tinha muito apoio, todo mundo
ficava só criticando aquelas coisas, mas daí “deu uns cinco minutos
em mim", e um dia eu falei:
"Quer saber de uma coisa, eu vou fazer também, porque assim vou
aprender a fazer projetos, se eu não fizer a gente não começa nun-
ca!" (Cláudia).

Sendo assim, desde a formalização de parcerias com a Associação Mato Dentro, a Fazenda São Luiz e a Escola Municipal do Ensino Fundamental Cassiana dos Santos Moreira, onde a idealizadora do Ponto de Cultura leciona, teve início a redação do projeto. Os argumentos de Cláudia explicitam uma desconfiança prévia à seleção, porque inúmeras eram as insinuações que a desmotivavam à propositura do projeto, deste modo sentia que: 
Estava aquele clima, uns dizendo que não sairia já, outros falavam que já tinham saído os pontos de algumas pessoas, que já sabiam de quem ia ser e aquelas coisas todas (Cláudia).

Em meio a receios e a desânimo, decidiu submeter o projeto:

Mas pensando que pelo menos eu ficaria com o projeto pronto, se eu não apresentasse para o Ponto de Cultura, eu poderia apresentar para outra entidade, buscar outros meios, pois a gente realmente estava precisando.

Cláudia posiciona o projeto como instância de mediação para ações futuras (Schutz, 1974), sob determinantes de seu campo de ação na cultura, sendo um destes a necessidade de recursos financeiros. Conforme seu relato, em entrevista, estavam passando por dificuldades financeiras intensas, de modo que os participantes da atividade colocavam dúvidas sobre a continuidade ou não do projeto.

Neste contexto de dificuldades financeiras, além de recursos que subsidiassem as despesas de outros atores associados à ação, outras despesas igualmente eram imediatas: passagens de ônibus para os participantes, combustível para o deslocamento do veículo pessoal da professora, especialmente se considerarmos que as apresentações do grupo muitas vezes exigiam deslocamentos de 70km. Embora Cláudia, em muitas situações, desembolsasse recursos próprios para tais demandas, identificava o auxílio financeiro aos participantes como um dos desafios prioritários. Em face da restrição de recursos, traço histórico das políticas culturais no país, decidiu escrever o projeto. Da decisão de escrever e os desafios pessoais da escrita, descreve:

Fiz o projeto, sentei, fiquei um mês sentada fazendo projeto, remoendo daqui, dali. Apagava, escrevia de novo, apagava, escrevia, apagava até a gente pensar realmente, amadurecer. Acho que foi amadurecendo a ideia na cabeça também para a gente ver o que realmente tinha que sair. Acabou saindo um projeto amplo, com várias coisas que eu estou testando dentro desse projeto (Cláudia).

O projeto era amplo e previa diversas atividades durante seus três anos de operacionalização. Da perspectiva das ações folclóricas previstas, inseriu: ensaios e apresentações de jongo ao longo do ano; ensaios e apresentações de Moçambique; formação de um grupo de Folia de Reis no bairro. Da perspectiva do financiamento, foram previstos recursos para: gasolina para os deslocamentos dos envolvidos; lanche para os estudantes nos dias de ensaio e apresentação; aquisição de equipamentos (computadores, um para edição de vídeo e outro para edição de música); produção de audiovisual. Uma perspectiva relevante deste projeto foi a política patrimonial das experiências desenvolvidas, a destacar a fotografia e a produção de vídeos documentários. 
Outra das dimensões importantes do projeto de Cláudia é o "Moçambique das Professoras", através do qual as mulheres são mobilizadas e convidadas a participar das atividades promovidas pelo Ponto de Cultura, com forte conteúdo de gênero. Novos agenciamentos, em forma e conteúdo, explicitam-se na narrativa de nossa informante, a saber:

Então, o que a gente tem divulgado é também assim: o popular é nosso, é a cara do Brasil. Até tenho divulgado muito isso, eu acho que o Brasil tem muito da cultura popular. O Brasil se organizou de uma maneira que a nossa cultura popular é muito rica, que a gente acrescentou, eu acho que misturou com as culturas regionais, com as culturas locais, a gente conseguiu traduzir isso em um povo que tem uma cultura muito própria, a gente tem os regionalismos que são muito fortes em cada região [...]. O Moçambique, a congada, as nossas danças da cultura popular também podem estar dentro de algumas academias, dentro de algumas universidades, não se modificando, se tornando cultura erudita eu acho, mas de maneira espontânea, divertindo, formando, agrupando pessoas, estar trabalhando e a gente continuar mostrando o que é nosso (Cláudia).

A narrativa cultural acima revela-nos que os sentidos atribuídos à cultura popular não são construídos como a priori, mesmo constatando que suas ancestralidades ou dimensões tradicionais estão na abertura do discurso. O significado das práticas é negociado entre os diferentes atores envolvidos, diante de seus agenciamentos socioculturais (Yúdice, 2004), o que produz novos fluxos de sentido à cultura. De certo modo, alguns ritos culturais atualizam-se na razão dos agenciamentos dos atores que os promovem, na perspectiva em que Pedro Martins definiu a reconstrução das manifestações expressivas, onde menciona que se referem à

categoria de análise que deve englobar todas as manifestações capazes de exprimir uma forma ou um conteúdo estético aliado a qualquer conteúdo identitário (Martins, 2009: 243).

Na situação definida, distribuíram um panfleto (Imagem 1) anunciando suas ações, com o selo de algumas entidades públicas (o que parece legitimar sua produção narrativa), quer seja por apoio financeiro através de editais públicos, ou através de associação a sua imagem, a saber: Governo do Estado de São Paulo, Ministério da Cultura (Ponto de Cultura, Mais Cultura) e Governo Federal. Além disso, explicita a configuração de mecanismos de reconstrução expositiva de manifestações culturais, pressupondo em seu discurso que a cultura popular está associada à prática de atividades físicas para mulheres, o que implica pensarmos que as políticas culturais, em circunstâncias como estas, operam dispositivos de seleção e adequação dos sentidos de seus objetos, ajustando-os a interesses objetivamente situados, através de técnicas específicas. Ou seja: 
na situação mencionada, fez-se produtiva a associação entre cultura popular e emagrecimento, a qual forja a emergência de um campo de problematizações essencialistas à cultura ("É para isso mesmo que serve a cultura popular?"), por um lado, mas, por outro, potencialmente engendra novas relações, sentidos, públicos e praticantes da mesma cultura, atualizando-a.

Outra característica deste modelo de agenciamento individual é o poder de mobilização. Em circunstâncias onde esta individualização dos agenciamentos se conforma e constitui um modelo, a agência situa-se em um campo de disputas individuais e reorganiza a pluralidade de forças (Simmel, 1946) no âmbito local, em boa medida, em correlação com a capacidade de mobilização e articulação de seus agentes. Cláudia explicita semelhante situação:
IMAGEM 1

PANFLETO CULTURAL

COM CHANCELA DE APOIO GOVERNAMENTAL

\section{PONTO DE CULTURA FAZENDA SÃO LUIZ Associação Mato Dentro \\ E.M.E.F "Cassiana dos Santos Moreira' PARCEIROS NO APOIO DA CULTURA POPULAR \\ DE SĀO LUIZ DO PARAITINGA-SP}

fale com a gente:(12) 97106020 - (12) 91118085

pontodeculturafazendasaoluiz@gmail.com

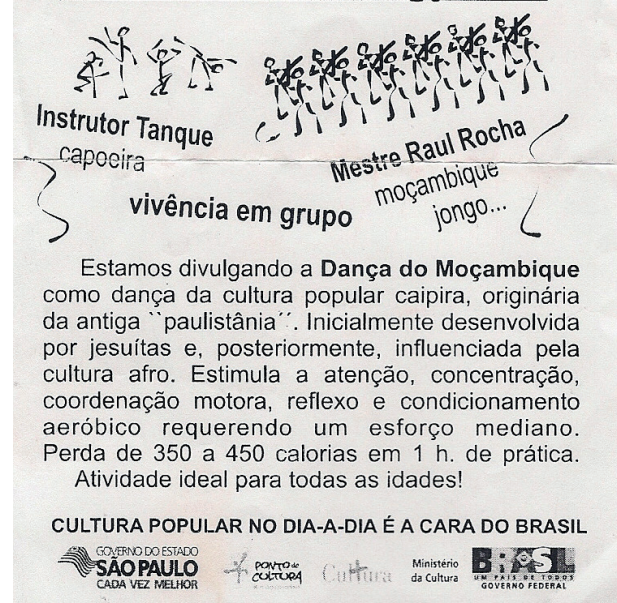

Assim, devagar, estou "tacando lenha na fogueira" lá no bairro, falta a gente ver o que a gente consegue fazer, como isso poderá acontecer e estou vendo que está dando fruto (Cláudia).

No caso do Moçambique das Professoras, tomam a escola, local de trabalho da proponente, como lócus privilegiado às ações do Ponto de Cultura. Aproveitam a presença dos estudantes na instituição de ensino, que passam a participar dos ensaios, principalmente por considerarem a distância onde muitos dos envolvidos moram. Utilizam espaços próximos na própria comunidade para a realização dos ensaios, como a capela do bairro, baseados nas relações pessoais da agente, ao mesmo tempo essa circunstância demonstra-nos não só a possibilidade de interiorização das políticas culturais brasileiras, como sua territorialização. Tais políticas articulam-se com as experiências vividas no lugar onde são implantadas.

Por fim, nossa interlocutora destaca a capacidade de financiar ações que antes não eram viabilizadas, em particular aquelas que garantem benefícios e incentivos às crianças que permanecerem no projeto. Quando analisa sua experiência, menciona ter dito inúmeras vezes: 
Um dia, eu preciso fazer um projeto para a gente ter uma grana para poder atender melhor mesmo as crianças e para a gente poder desenvolver melhor esses mesmos projetos (Cláudia).

Com isso, ressalta a importância do Programa Cultura Viva para a efetuação qualificada de experiências prévias no campo cultural e, de certo modo, do quanto este projeto potencializa estratégias futuras, incorporado-se à gramática das políticas culturais, em especial em São Luiz do Paraitinga.

\section{Considerações finais}

Os modelos de agenciamento cultural analisados neste artigo configuram técnicas de vida (Simmel, 1979) ao se constituírem em determinantes que estabelecem limites específicos que condicionam a ação dos indivíduos nas políticas culturais contemporâneas. Desde a análise que realizamos, identificamos pesos e influências distintas entre fatores econômicos, políticos e sociais que tangenciam os projetos culturais, algumas vezes mais próximos de políticas nacionais de cultura, como o imperativo da lógica de editais na seleção de programas ou as leis de incentivo em suas faces específicas, outras vezes mais aproximados das práticas sociais dos atores participantes deste campo, como os agenciamentos pessoais ou os interesses locais em jogo. Porém, duas características são recorrentes nesta interpretação dos modelos: o interesse na institucionalização do projeto cultural e a conformação de um novo arranjo das forças plurais (Simmel, 1946) em dinâmicas competitivas ou concorrenciais. Variações dessas características permitem a análise da emergência de dois modelos de agenciamento cultural, não dicotômicos, mas com observável predominância de umas ou outras ênfases em perspectiva, as quais, obviamente, são construídas desde tipificações ilustrativas, não podendo ser encontradas em "estado puro" na realidade social. Deste modo, reconhecemos a possibilidade de existência de outros modelos, ou mesmo modelos em transição ou interseção.

O primeiro modelo, descrito desde experiências em políticas culturais em Gramado (RS), é o agenciamento cultural de Estado. A institucionalização dos projetos dá-se na criação de organizações burocráticas intermediárias e na potencialidade de o próprio Estado atuar como agente cultural, cujas manifestações são: dispositivos de racionalização das ações (manipulação de planos, estratégias, objetivos político-organizacionais); seletividade de atores e iniciativas adequadas ou desejáveis ao projeto municipal de turismo/cultura e consequente modulação de campos não-autônomos de produção cultural; criação de setores especializados em formulação de projetos e acompanhamento de editais, tornando a formulação de projetos um exercício permanente. Assim, forma-se um campo concorrencial exógeno ao município, o que muda a escala de competitividade de projetos e iniciativas, reconhe- 
cendo que a dinâmica socioeconômica da cidade depende dos projetos culturais - turísticos, sobretudo.

O segundo modelo, por sua vez, identificado nas disputas por Pontos de Cultura em São Luiz do Paraitinga (SP), é o de agenciamentos individuais. A institucionalização dos projetos dá-se por meio de dispositivos de racionalização das ações (planos, estratégias, objetivos político-organizacionais) - como no modelo anterior. Porém, estes projetos exigem agenciamentos em um campo de disputas individuais e forças postas no âmbito local, os quais são realizados desde relações pessoais, familiares, profissionais e políticas de seus proponentes. Estas disputas e concorrências reorganizam as "forças plurais" na cidade, personalizando a identificação entre o projeto e seu idealizador. Desta maneira, forma campos concorrenciais endógenos ao município, entre projetos e agentes portadores de experiências prévias (Schutz, 1974) voltados à efetuação de iniciativas que reformulem ou ampliem ações em curso. Se, no primeiro modelo, as experiências oportunas referem-se àquelas já instituídas na municipalidade (edições anteriores de eventos, feiras, roteiros de planejamento de custos e ações), no modelo dos agenciamentos individuais os projetos são desenvolvidos segundo as experiências e "conhecimentos que seus atores dispõem à mão" (Schutz, 1974) no momento, o que correlaciona projeto cultural e suas experiências sociais, com maior autonomia dos atores à formulação de projeções.

Esses novos cenários de mudanças político-institucionais desafiam as políticas culturais de nosso tempo, uma vez que proporcionam a irradiação de múltiplos agenciamentos culturais. Os agenciamentos analisados explicitam uma ambivalência entre a construção de um campo concorrencial entre projetos e os atores culturais em busca de diversos recursos (Yúdice, 2004) e a reconfiguração de modelos valorativos voltados para a reconstrução dos sentidos sociais (Dewey, 1970), nas mesmas políticas.

Portanto, implica pensarmos que a racionalização dos agenciamentos culturais, através de editais de concorrência, como técnica de vida contemporânea (Silva, 2012a), consolida um campo identificável de experiências competitivas entre atores, mesmo que, ao mesmo tempo, apresente contribuições para a formação de um modelo valorativo de democratização destas políticas, uma vez que atua na produção de disputas mais claras e potencialmente justas por recursos públicos, o que busca evitar o clientelismo e o patrimonialismo típico das relações entre os atores e o Estado, no Brasil.

Abstract: The paper aims at high lighting a set of institutional changes undergone by contemporary cultural policies in Brazil, on a national scale, and understand how these settings produced new forms of cultural agency and political action, at local scales. For this purpose, initially, there was a 
review at Brazilian cultural policies, as literature. Then, through systematic monitoring of cultural policies in two Brazilian cities - Gramado (RS) and São Luiz do Paraitinga (SP) - analyzed its implementation and the modes of action of the actors in these processes, considering its tensions, disputes and interests at stake.

Keywords: cultural policies; cultural action; agencies; institutional changes.

\section{Referências}

Agler, M. Distúrbios identitários em tempos de globalização. Mana, v. 7, n. 2. Rio de Janeiro, 2001, p. 7-33, .

Albuquerque JR., D. M. Fragmentos do discurso cultural: por uma análise crítica do discurso sobre a cultura no Brasil. In: Nussbaumer, G. (Org.). Teorias e políticas da cultura: visões multidisciplinares. Salvador: Edufba, 2007, p. 13-24.

Anderson, P. Balanço do neoliberalismo. In: SAder, E.; Gentilı, P. (Org.). Pós-neoliberalismo: as políticas sociais e o Estado Democrático. São Paulo: Paz e Terra, 1998, p. 9-23.

Barbalmo, A. Políticas culturais no Brasil: identidade e diversidade sem diferença. In: Rubim, A. A. C.; Barbalho, A. (Org.). Políticas culturais no Brasil. Salvador: Edufba, 2007, p. 37-60.

BARBosa, F. Ministério da Cultura no governo Luiz Inácio Lula da Silva: um primeiro balanço. In: CALABRE, L. (Org.). Políticas culturais: um campo de estudo. Rio de Janeiro: Casa Rui Barbosa, 2008, p. 59-86.

BotelHo, I. Políticas culturais: discutindo pressupostos. In: Nussbaumer, G. (Org.). Teorias e políticas da cultura: visões multidisciplinares. Salvador: Edufba, 2007, p. 171-180.

CALABRE, L. Gestão cultural: análises e perspectivas das propostas da I Conferência Nacional de Cultura. In: CALABRE, L. (Org.). Políticas culturais: um campo de estudos. Rio de Janeiro: Casa Rui Barbosa, 2008, p. 117-136.

. Políticas culturais no Brasil: dos anos 1930 ao século XXI. Rio de Janeiro: Editora FGV, 2009.

CANCLINI, N. G. A globalização imaginada. São Paulo: Iluminuras, 2003.

CASTEL, R. As transformações da questão social. In: BelfiORE-WANDERLEY, M.; BóGUS, L.; YASBEK, M. C. Desigualdade e a questão social. 2. ed. São Paulo: Educ, 2004, p. 235-272.

Chauí, M. Cidadania cultural: o direito à cultura. São Paulo: Perseu Abramo, 2006.

CURY, C. E. Políticas culturais no Brasil: subsídios para a construção da brasilidade. 2002. Tese (Doutorado em Educação) - Universidade Estadual de Campinas, Campinas (SP). 
DEWEY, J. Liberalismo, liberdade e cultura. São Paulo: Editora Nacional; USP, 1970.

LOPES, J. R. Industrialização e mudanças culturais no vale do Paraíba, SP. In: CHAMON, E. M. Q. O.; SouSA, C. M. (Org.). Estudos interdisciplinares em ciências sociais. Taubaté: Cabral, 2006.

LOPES, J. R; SILVA, A. L.; SILVA, R. M. D. O Divino, o patrimônio e a cidade: uma análise de modulações culturais provocadas por eventos críticos. Ciências Sociais Unisinos, v. 47, n. 3. São Leopoldo, 2011, p. 208-217.

MARTINS, P. Cabo-verdianos em Lisboa: manifestações expressivas e reconstrução identitária. Horizontes Antropológicos, n. 31. Porto Alegre, 2009, p. 241-269.

OLIVEN, R. G. Urbanização e mudança social no Brasil. Petrópolis: Vozes, 1980.

ORTIZ, R. A moderna tradição brasileira: cultura brasileira e indústria cultural. São Paulo: Brasiliense, 1988.

Pereira, L. Ensaios de sociologia do desenvolvimento. São Paulo: Pioneira, 1970.

Rubim, A. A. C.; Barbalho, A. (Org.) Políticas culturais no Brasil. Salvador: Edufba, 2007.

RUbim, A. A. C. Políticas culturais: entre o possível e o impossível. In: NussbaUmer, G. (Org.). Teorias e políticas da cultura: visões multidisciplinares. Salvador: Edufba, 2007, p. 139-157.

As políticas culturais e o governo Lula. São Paulo: Perseu Abramo, 2011.

Santos, J. R. C. C. A festa do Divino de São Luiz do Paraitinga: o desafio da cultura popular na contemporaneidade. 2008. Dissertação (Mestrado em História Social) Universidade de São Paulo, São Paulo.

SCHUTZ, A. El problema de la realidad social. Buenos Aires: Amorrortu, 1974.

SILVA, A. L. A conveniência da cultura popular: um estudo sobre a pluralidade de domínios, danças devocionais e a ação dos mestres no Vale do Paraíba. 2011. Tese (Doutorado em Ciências Sociais) - Pontifícia Universidade Católica de São Paulo, São Paulo.

SILVA, R. M. D. Políticas culturais em cidades turísticas brasileiras: um estudo sobre as técnicas de vida contemporâneas. 2012a. Tese (Doutorado em Ciências Sociais) - Universidade do Vale do Rio dos Sinos, São Leopoldo (RS).

- Políticas culturais e narrativas de reconstrução social em São Luiz do Paraitinga, SP. Políticas Culturais em Revista, v. 5, n. 1. 2012b, p. 126-141.

SIMmeL, G. Cultura femenina y otros ensayos. 5. ed. Buenos Aires: Espasa-Calpe, 1946. 
—. A metrópole a vida mental. In: VELHO, O. (Org.). O fenômeno urbano. 4. ed. Rio de Janeiro: Zahar, 1979.

- Sociabilidade: um exemplo de sociologia pura ou formal. In: MORAES FILHO, Evaristo (Org.). Simmel: sociologia. São Paulo: Ática, 1983.

SouzA, C. O estado do campo da pesquisa em políticas públicas no Brasil. Revista Brasileira de Ciências Sociais, v. 18, n. 51. Anpocs, 2003, p. 15-20.

URRY, J. O olhar do turista: lazer e viagens nas sociedades contemporâneas. São Paulo: Sesc; Nobel, 1996.

VIEIRA, E. Estado e miséria social no Brasil: de Getúlio a Geisel. São Paulo: Cortez, 1983.

WEBER, M. Economia e sociedade: fundamentos da sociologia compreensiva. v. 2. Brasília: Editora Unb, 1999.

YúDICE, G. A conveniência da cultura: usos da cultura na era global. Belo Horizonte: Editora UFMG, 2004. 